\title{
Hypophosphatasia - Recent Advances in Diagnosis and Treatment
}

\author{
Beck C. ${ }^{1}$, Morbach H. ${ }^{1}$, Stenzel M. ${ }^{2}$, Collmann H. ${ }^{4}$, Schneider P. ${ }^{3}$ and Girschick H.J. ${ }^{*}$ \\ ${ }^{I}$ Children's hospital, Section of Pediatric Rheumatology, Osteology, Immunology and Infectious Diseases, ${ }^{2}$ Institute of \\ Radiodiagnostics, Department of Pediatric Radiology, ${ }^{3}$ Clinic of Nuclear Medicine, ${ }^{4}$ Department of Pediatric \\ Neurosurgery, University of Wuerzburg, Josef-Schneider-Str. 2, 97090 Wuerzburg, Germany
}

\begin{abstract}
Hypophosphatasia (HP) is a rare inborn error of bone and mineral metabolism transmitted as an autosomalrecessive trait. It is characterized by a reduced activity of the tissue-nonspecific isoenzyme of alkaline phosphatase (TNSAP) and elevated concentrations of its substrates including pyrophosphates. Clinical symptoms include defective bone mineralisation with bone deformities, fractures and recently defined chronic non-bacterial osteomyelitis. Renal damage due to calcification, dental abnormalities with premature loss of dentition and craniosynostosis are further symptoms. Knowledge on the mechanisms underlying cell activation leading to inflammation and tissue destruction is still limited in HP. Recent investigations have provided evidence that calcium pyrophosphate crystals are essentially involved in activating inflammatory signal transduction pathways via different receptors of the innate immune system. Further studies are needed to improve our understanding of the pathophysiological mechanisms leading to inflammation and tissue destruction associated with deposition of microcrystals. They might support the development of new therapeutic strategies for crystal-induced inflammation. Laboratory assays, genetic analysis and radiographic imaging can confirm the diagnosis. Since clinical symptoms are highly variable patients should be followed by a HP-experienced multidisciplinary team (paediatrician, radiologist, orthopedic surgeon, neurosurgeon, dentist, nutritional specialist). At the moment symptomatic treatment is most important because curative or causative therapies, like gene transfer or enzyme replacement therapy, are not yet available.
\end{abstract}

\section{INTRODUCTION}

Hypophosphatasia (HP) is an inborn error of bone and mineral metabolism first recognized more than 50 years ago. It is caused by various defects in the gene coding for the tissue non-specific alkaline phosphatase (TNSAP) located on chromosome $1 \mathrm{p} 36.1$ and results in elevated concentrations of its substrates [1, 2]. Until now more than 190 different mutations have been identified causing deficiency of TNSAP [3]. Knowledge whether accumulating substrates of TNSAP are pathophysiologically associated with hypomineralization of bone, resulting in bone deformities, fractures, short stature, gout/arthrotic-like symptoms or pain, is still limited [3-6]. The frequency of HP has been estimated to be 1:100.000/inhabitants. The prevalence of affected children in Germany has been estimated to be around 200. Diagnosis of the disease is often complicated by rareness of the disease. In addition, symptoms vary in their clinical expression and can resemble other skeletal diseases. Thus, the number of unknown cases especially with mild forms seems high because of limited medical knowledge and awareness. Due to the predominant autosomal recessive inheritance defective genes can be passed in families unidentified for a long time.

Genetic studies showed a good genotype - phenotype correlation, which means that patients with mild HP carry at least one mutation of significant residual enzymatic activity,

*Address correspondence to this author at the Children's hospital, University of Wuerzburg, Josef-Schneider-Str. 2, 97090 Wuerzburg, Germany; Tel: 0049931 20127728; Fax: 0049931 20127720; E-mail: Hermann.Girschick@mail.uni-wuerzburg.de while patients with severe HP carry mutations that mostly do not produce residual enzymatic activity [3].

\section{CLINICAL SIGNS AND CLASSIFICATION}

Based on clinical courses and severity, HP has been divided into 5 major subtypes. The perinatal form is the most severe one. It results in stillbirth or death a few days after birth due to hypoplastic lungs, difficult to treat seizures, extensive hypomineralisation, deformities of bone and disturbances of the $\mathrm{Ca} / \mathrm{P}$ metabolism [7]. Recently a mild form of perinatally diagnosed HP has been described: Prenatally bowed legs were no longer present at birth. A long-term follow-up on this child is unknown so far. Clinical signs of the infantile form appear during the first 6 months of life including rickets, premature craniosynostosis, irritability, seizures and nephrocalcinosis due to hypercal-ciuria $[1,8]$. Death within the first year of life is common. The childhood form in most cases presents after the first year of life and is characterized by rickets causing a short stature, delayed walking and a waddling gait due to bone deformities and pain of the lower extremities. Premature loss of teeth often leads to diagnosis (Fig. 1) [2, 3, 5, 9]. Adult HP presents with osteomalacia, chondrocalcinosis, osteo-arthropathy and stress fractures during middle age in patients who had a history of mild rickets in childhood [1,3]. Odontohypophosphatasia has been characterized by premature exfoliation of primary teeth and/or severe dental caries, often not associated with abnormalities of the skeletal system $[1,3,5]$. However, it should be noticed that these five clinical subtypes can overlap significantly, for example patients with adult hypophosphatasia often had musculoskeletal symptoms 


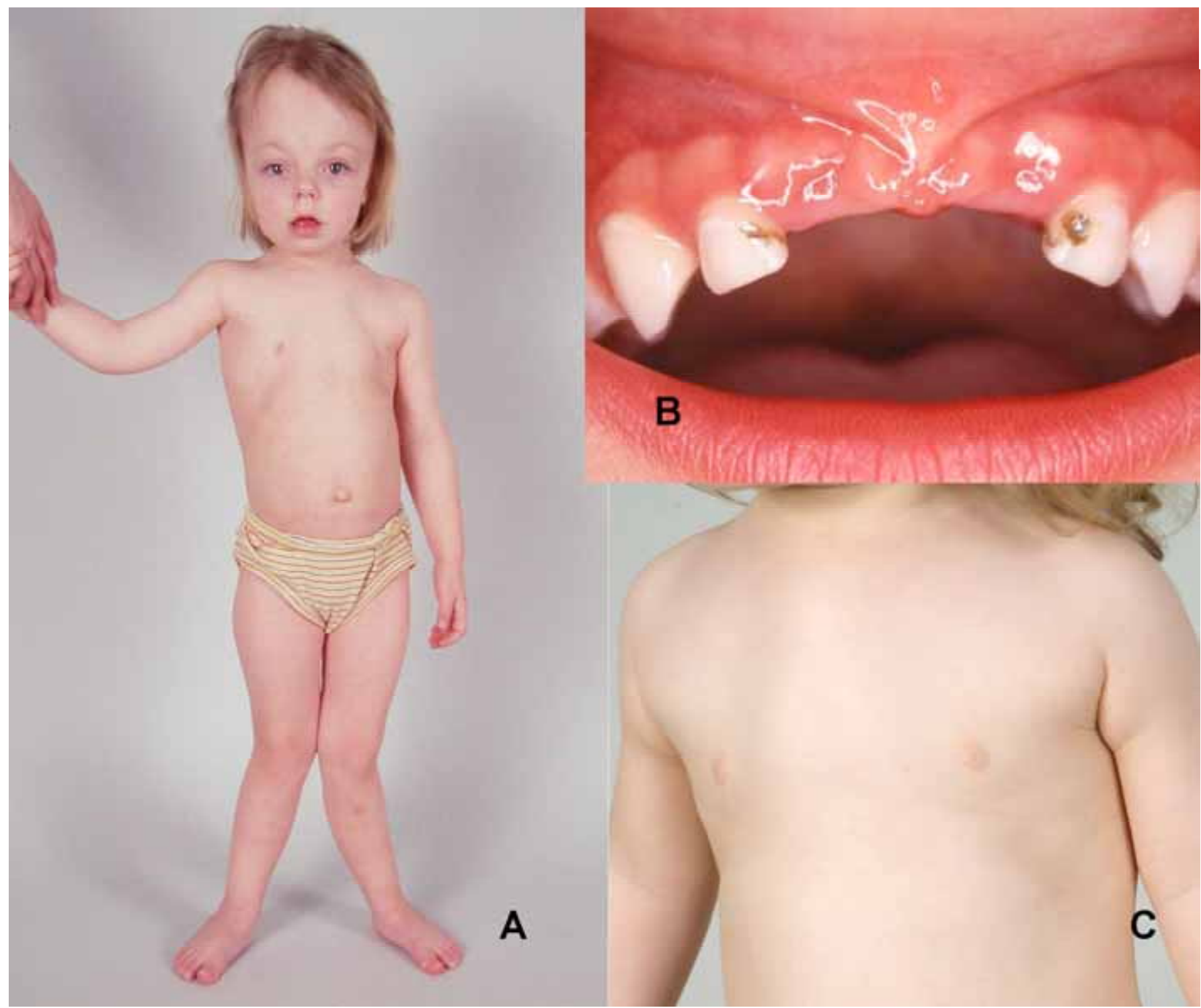

Fig. (1). Clinical symptoms of the infantile-juvenile form of HP: A. shows a whole body photography of a child with genua valga, thorax deformity, craniosynostosis and short stature. B. demonstrates premature exfoliation of primary teeth and dental caries. C. illustrates the thorax deformity.

already in childhood. The infantile and the childhood form might be difficult to distinguish, because early symptoms might be present in the first months of life in both "subtypes".

In addition, dental abnormalities are frequent in childhood and adult HP and consist of abnormal enamel, dentin, and cementum formation, increased pulp spaces and premature loss of predominantly the first, but also the permanent dentition [10]. Patients often complain about pain, stiffness, and weakness of the lower limbs, which may be caused by microfractures of hypomineralized and structurally insufficient bone. In addition, deposition of calcium pyrophosphate or phosphate crystals in the periarticular zone or in soft tissues may result in an acute inflammation with excessive production of prostaglandins $[5,11,12]$.

Differential diagnosis includes osteoporosis, rickets, osteogenesis imperfecta, M. Paget, achondroplasia, periodontitis as well as osteosarcoma.

\section{ETIOLOGY AND PATHOGENESIS}

TNSAP is an isoenzyme of alkaline phosphatase (AP). It is a membrane-bound glycoprotein which seems to be of major relevance for crystallization of hydroxyapatite and, thus, skeletal and dental mineralization $[4,6]$. The exact function of the TNSAP with regard to bone formation is still uncertain but involves hydrolysis of inorganic pyrophosphate or phosphate-phosphate bonds resulting out of the energy metabolism (ATP -> AMP and PP). Phosphate can be generated in this way, subsequently it is associated with calcium in special excrescences of osteoblasts to form hydroxyapatite, which is the structural basis of bone enclosed in the collagen matrix $[1,2,4,6]$. Although the range of mutations that are responsible for $\mathrm{HP}$ is wide, a particular pattern of positioning of the mutated enzyme has been reported: Missense mutations found in severe HP produced a mutant protein that failed to reach the cell membrane and was subsequently degraded. In contrast, the 


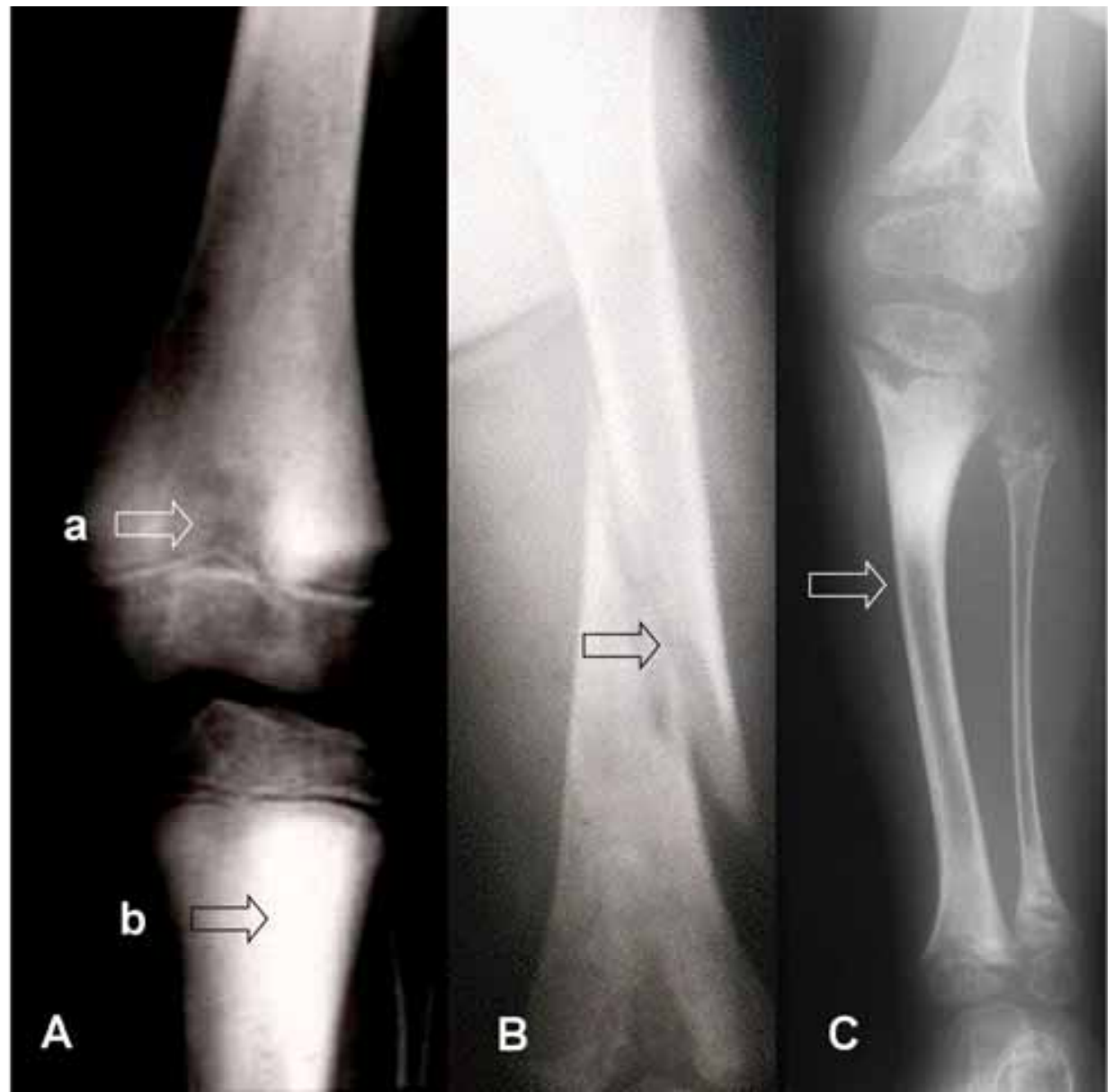

Fig. (2). Radiographic imaging: A. An X-ray of the right knee with radiographic features characteristic for HP including inhomogeneous bone structure with hypomineralized (Looser-zones, arrow a) and compensatory hypermineralized regions (arrow b). B. A femoral fracture after an inadequate trauma. An inhomogeneous metaphyseal bone structure is present. C. Demonstrates bone deformity of the lower extremities.

missense mutations responsible for mild HP were found to be, at least in part, correctly localized in the cell membrane [13]. Reduced activity of TNSAP results in an insufficient bone mineralization with soft and brittle bones that tend to fracture or deform [5] (Fig. 2). In HP the cementum of teeth often has a wrong structure or is totally missing. Because of that the teeth holding apparatus is formed incorrectly with reduced vertical development of the teeth. Loss of teeth is the consequence of the insufficient fixation of roots in the bone and of resorption of the direct contact between root dentin and the bone. Hypoplasia of enamel as a risk factor for severe dental caries also has been described [10].

Furthermore, reduced activity of TNSAP results in accumulation of its metabolic products. Elevated concentrations of pyridoxal-5' -phosphate, inorganic pyrophosphate and phosphoethanolamine can be detected in serum, tissues and urine $[1,5]$. Especially inorganic pyrophosphate actively inhibits bone mineralization. It unites with calcium outside the osteoblasts and deposits in crystallized form in joints, muscles, arteries and kidneys and, thus, causes a "saltiness" of tissues. In this regard, we have documented that chronic bone inflammation can play a decisive role in many HP patients. These inflammatory conditions obviously seem to be a result of the enzymatic defect and are caused, at least in part, by the accumulation of non degraded TNSAP substrates, especially by calcium-pyrophosphate crystals (CPPD). Similar to monosodium urate crystals in gout these crystals can give rise to inflammatory processes $[9,12$, 14-17]. Knowledge on the mechanisms underlying these crystal-induced cell activation, however, is limited. We have summarized recent advances in elucidating the signal transduction pathways activated by CPPD crystals as endogenous “danger signals". Recent investigations provided evidence that Toll/interleukin-1 receptor (TIR) domain containing receptors including toll-like receptors (TLRs) and the interleukin-1 receptor (IL-1R), as well as the triggering receptor expressed on myeloid cells 1 (TREM-1) and the NALP3 (NACHT-leucin rich repeat and pyrin-domaincontaining protein) containing inflammasome are essentially involved in acute CPPD crystal-induced inflammation [14, 16, 18-37]. These receptors are considered in part as components of the innate immune system. Activation of various complex signalling cascades results in secretion of proinflammatory cytokines, chemokines and matrix metalloproteinases. Especially IL-1ß seems to be a key player in crystal-induced acute inflammation [9, 19, 33, 38-42].

Further studies are needed to improve our understanding of the pathophysiological mechanisms leading to inflammation and tissue destruction associated with deposition of 


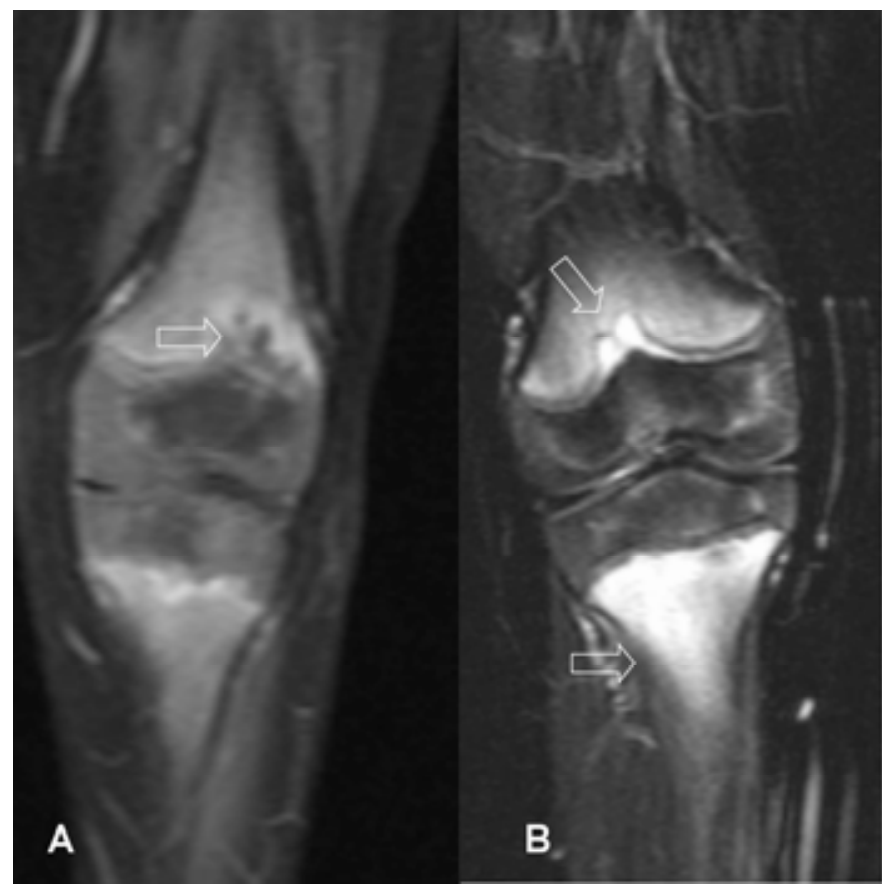

Fig. (3). Magnetic resonance imaging of the knee: A. (T1-weighted with fat suppression after i.v. gadolinium DTPA application): significant signal elevation in the metaphyses and diaphyses characteristic of a higher vascularisation. B. (T2-weighted with fat suppression): significant signal elevation in the metaphyses, which can be interpreted as bone oedema.

microcrystals. They might support the development of new therapeutic strategies for crystal-induced inflammation. Eventually, also patients with HP might profit from such strategies addressing these metabolic disorders secondary to the gene defect.

We were able to show that in the childhood form of HP most children produce high levels of prostaglandin E. This hyperprostaglandinism might intervene with the bone metabolism $[12,15]$. Prostaglandin production can be inhibited with prostaglandin synthesis inhibitors (non-steroidal antiinflammatory drugs, NSAID). Whether other problems of
HP, like craniostenosis (Fig. 4), are linked with an inflammatory reaction in the bone is still a focus of research (Fig. 3). We have noticed that histologically comparable inflammatory processes are present in another rare disease, the chronic non-bacterial osteomyelitis CNO (prevalence in Germany around 10/100000 children). In 4 out of 100 children affected clinically by $\mathrm{CNO}$ we were able to find TNSAP gene defects, because their AP levels were too low. In this way two rare diseases with a comparable disease manifestation were linked in their pathophysiology [11, 15, 43].

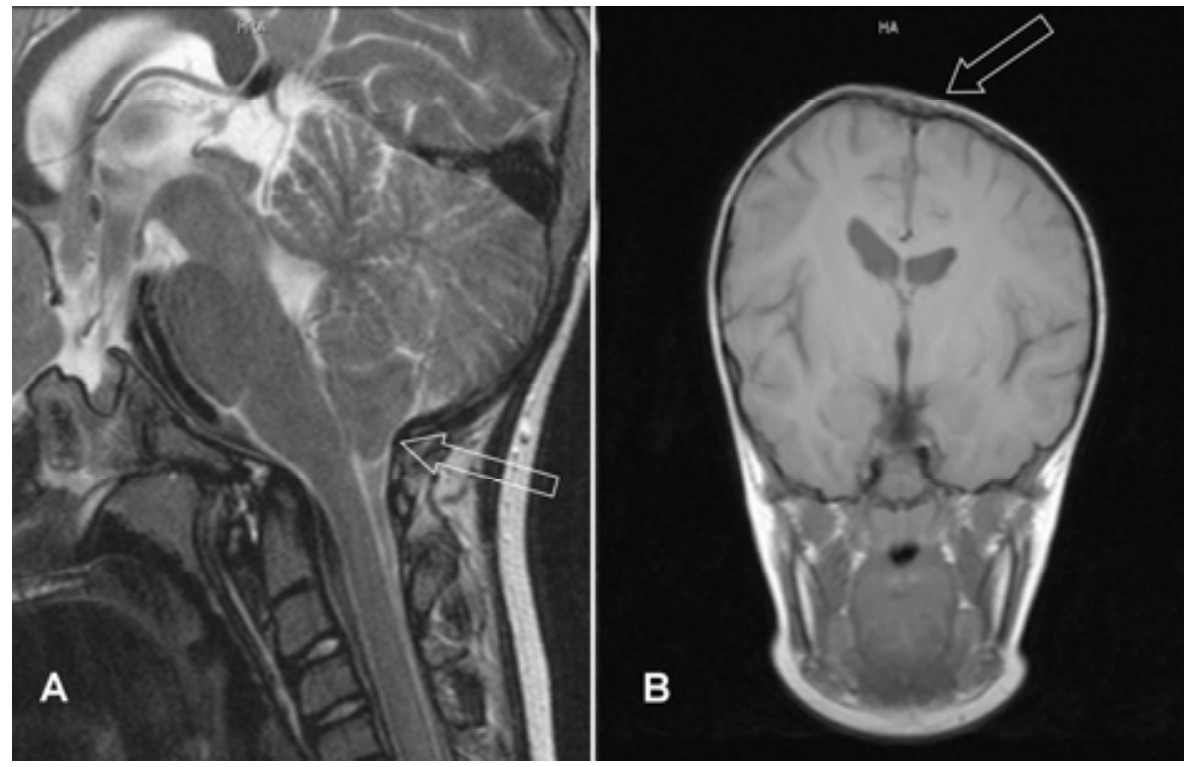

Fig. (4). Cranial magnetic resonance imaging: A. (T2-weighted) demonstrates mild tonsillar herniation in a 4 year old HP patient. B. (T1weighted) shows plagiocephalus due to partial closure of sutures. 
Especially the etiology and pathogenesis of gastrointestinal symptoms, like loss of appatite, nausea and digestive irritation as well as neurological symptoms (seizures, epilepsia and pseudo-meningitis) in HP patients are still unclear. Recently it has been shown that seizures in severe HP can be ameliorated by non-phosphated vitamin B6 (pyridoxine) [8]. Pyridoxal 5'-phosphate (PLP), the active metabolite of vitamin B6, is an essential coenzyme for the synthesis of various neurotransmitters and biogenic amines. The plasma membrane-bound ectoenzyme TNSAP dephosphorylates PLP to pyridoxal (PL). That form of vitamin B6 can cross cell plasma membranes and is phosphorylated again intracellularly to PLP. The common explanations for seizures in severe HP are a low intracellular brain PLP-level and a reduced PLP-dependent synthesis of neurotransmitters, both lowering the seizure threshold [8].

Further studies are needed to understand the secondary effects associated with this inborn defect of bone metabolism. Since patients with milder forms do not experience a reduced life span, there is considerably more time for such secondary phenomena to influence the HP phenotype.

\section{DIAGNOSTIC METHODS}

Diagnosis of HP often causes considerable problems. On the one hand it is a rare disease with a variety of differential diagnoses. On the other hand different HP subtypes present a partly comparable spectrum of symptoms. On the website www.hypophosphatasie.net differential diagnosis of HP is described.

In addition to the clinical symptoms mentioned above, diagnosis is based on laboratory assays, genetic counselling and radiographic imaging (Table 1). Prenatal assessment by mutational analysis of chorionic villus DNA is possible. After birth total serum AP activity or TNSAP measured in leukocytes, respectively, are below the age-related normal

Table 1. Diagnostic Procedures in HP

\begin{tabular}{|l|}
\hline \multicolumn{1}{|c|}{ Clinical Symptoms } \\
\hline Laboratory testing: \\
$\qquad \begin{array}{l}\text { decreased: AP in serum, TNSAP in leukocytes } \\
\text { increased: iPP, PEA, PLP in serum or urine } \\
\text { possible disturbance: calcium und phosphate } \\
\text { metabolism } \\
\text { renal function tests }\end{array}$ \\
\hline Radiological imaging: X-ray, MRI, if necessary whole body-MRI \\
\hline Sonography of kidneys \\
\hline Bone mineral density: pQCT, DEXA \\
\hline Dentist/orthodontist examination \\
\hline Neurological examination \\
\hline Ophthalmoscopic examination \\
\hline Genetic testing \\
\hline
\end{tabular}

range. AP activity depends on age, sex and on laboratory procedures. However, a reduced AP activity is only a helpful diagnostic indicator but it is not HP specific. Other conditions may also show reduced levels of AP including early pregnancy, hypothyroidism, anaemia, celiac disease or zinc deficiency [2, 4]. In general, residual serum AP activity has directly been linked to disease activity (Table 2). Patients with perinatal forms often have a total serum AP below 10$20 \mathrm{IU} / \mathrm{l}$, whereas a milder form (infantile or childhood form) has to be considered, if AP values are around or slightly below the lower limit (below $100 \mathrm{IU} / \mathrm{l}$ ). In particular, patients with singular heterozygous mutations or autosomal dominant inheritance often exhibit a considerable residual AP activity. Separation of an autosomal dominant with a compound heterozygous disease state or a singular heterozygous carrier status on the basis of the biochemical AP activity is usually impossible.

Table 2. Laboratory Testing

\begin{tabular}{|lc|}
\hline \multicolumn{2}{|l|}{ Alkaline Phosphatase: } \\
\hline \multicolumn{2}{|l|}{ AP in serum $\left(37^{\circ} \mathrm{C}\right.$, IFCC method): } \\
\hline Infants & $110-590 \mathrm{IU} / \mathrm{l}$ \\
\hline Toddlers & $110-550 \mathrm{IU} / \mathrm{l}$ \\
\hline Pupils & $130-700 \mathrm{IU} / \mathrm{l}$ \\
\hline Women & $65-147 \mathrm{IU} / \mathrm{l}$ \\
\hline Man & TNSAP in leukocytes: $2-18 \mathrm{nmol} / \mathrm{min} \mathrm{mg}$ protein \\
\hline PLP in plasma: $5-30 \mathrm{ng} / \mathrm{ml}$ \\
\hline PEA in serum/plasma: $0-60 \mu \mathrm{mol} / \mathrm{l}$ \\
\hline PEA/creatinine in urin: $9-25 \mathrm{mmol} / \mathrm{mol}$ creatinine \\
\hline
\end{tabular}

The reference ranges are those of normal values of the authors laboratory, in particular appropriate for the diagnosis of childhood HP. Variations depending on age, sex and laboratory conditions etc. are possible [16].

Reduced enzyme activity results in accumulation of its substrates including pyridoxal-5' -phosphate, inorganic pyrophosphate and phosphoethanolamine which can be detected in serum, tissues and urine [1,2]. Often serum calcium and phosphate are normal or slightly increased. Urinary calcium excretion might be above the normal range. Careful surveillance including ophthalmologic and neurologic examination is recommended in patients with cranios-tenosis, eventually complemented by an invasive epidural monitoring of intracranial pressure (Fig. 4).

Sequencing of the TNSAP gene is essential to confirm the diagnosis of hypophosphatasia when biochemical and clinical data are not clear enough or in the prenatal assessment of severe hypophosphatasia in couples with a previously affected child or pregnancy [1,3]. Only a few laboratories in Europe routinely do perform genetic TNSAP analysis (see www.hypophosphatasie.net). Genetic consultation is recommended before genetic testing is done. Genetic testing of the patient's relatives seems useful as heterozygous may express a mild form of the disease [5].

The HP multidisciplinary management includes monitoring of patents by HP-experienced dentists or orthodontists. Furthermore we recommend bone mineral density measurements using peripheral quantitative computed tomography (pQCT) and dual energy X-ray absorptiometry (DEXA). In our patients we demonstrated focal bone defects, hypomineralized cortical bone next to compensatory scle- 


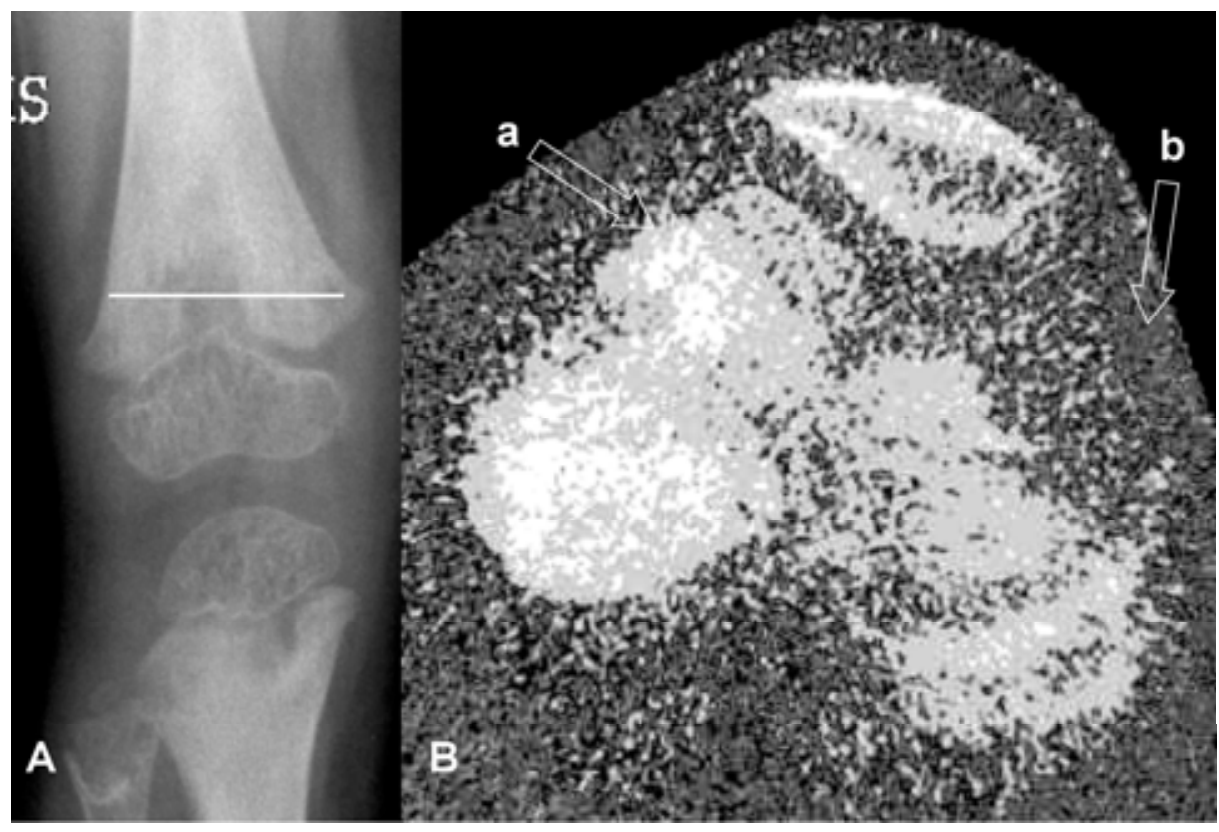

Fig. (5). Bone mineral density: Conventional X-ray of the distal right femur (white line depicts the measurement zone by pQCT) and peripheral quantitative computed tomography (pQCT) of the distal femoral metaphysis of a 10 year old patient showing local areas of higher bone density present in the trabecular bone (arrow, a). In contrast, the cortical bone of the femur is undermineralized (arrow, b).

rosis/hypermineralization of metaphyseal trabecular bone. This unexpected finding might be the mechanical and structural consequence of an insufficient bony structure in HP. Mechanical forces together with a hyperprostaglandinism could be the causes of this still unexplained phenomenon (15) (Fig. 5).

\section{MANAGEMENT AND TREATMENT}

At the moment there is no curative treatment of hypophosphatasia. Therefore, symptomatic treatment in order to improve the clinical features, especially with regard to pain, seizures and other metabolic phenomena (e.g. nephrocalcinosis) is of major interest. We have previously described the presence of hyperprostaglandinism in childhood HP. An anti-inflammatory treatment using NSAIDs resulted in a significant improvement of physical activity, a reduction in pain-related complaints and normalization of prostaglandin (PG) levels $[9,12]$. After drug withdrawal, the positive effect persisted for another 3-6 weeks. NSAID treatment was safe and should be considered in patients with significant complaints about pain [9]. In adult HP teriparatide treatment has been reported to be successful in two patients so far $[44,45]$. However, there are no controlled studies available.

Treatment with zinc and magnesium, the catalytic ions of the enzyme, and pyridoxal 5 -phosphate were reported to have no significant long-term benefit for HP patients. Dietary phosphate restriction is recommended for patients with high serum levels of phosphate. Especially for children with persistent growth retardation an adequate nutrition with the support of a professional dietician is of major importance. Supplementation with vitamin D can be recommended according to the guidelines for healthy children. Further additional vitamin D therapy, as it is used in vitamin D deficient rickets, should be avoided. An additional supplementation of calcium may result in hypercalcemia and formation of kidney stones. Treatment strategies should be monitored permanently in a HP-experienced clinic. Physical exercises like cycling and swimming as well as physiotherapy seem to be useful tools for muscle building in order to stabilize the skeleton. Whether a physical workout leads to appositional growth of bone in HP has not been evaluated so far. The maintenance of physical function is of major importance. Especially in severe forms of disease trauma to the skeleton must be avoided because resulting fractures take a long time to heal and might be difficult to treat. Surgical as well as conservative therapeutic approaches should be discussed with a HP-experienced clinical center.

Premature fusion of cranial sutures may result in secondary ectopia of the cerebellar tonsils (Chiari I malformation) or formation of hydrosyringomyelia (Fig. 4). Neurosurgical interventions are necessary in patients with neurologic symptoms like permanent headache, seizures, paralysis or numbness of extremities as well as papilledema due to elevated intracranial pressure. With regard to the progressive nature of craniosynostosis careful surveillance including ophthalmoscopic reassessment, neurologic examination and radiographic imaging is recommended throughout childhood until adolescence, and, in presence of Chiari I malformation or hydrosyringomyelia, probably throughout lifetime [41].

Dental monitoring by a HP-experienced dentist or orthodontist seems to be very important. Prosthetic replacement of prematurely lost teeth may be helpful for linguistic development and social integration of patients in preschool or school. Possible loosening of remaining teeth should be noted in planning removable dentures. Periodical dental supervisions are essential. Impaired transversal development (width of jaw) of front teeth in the upper and lower jaw due to premature exfoliation of primary teeth may result in a non-alignment of permanent front teeth. Corrections of such 
incorrect teeth positions are possible but should be coordinated by a HP-experienced orthodontist.

Enzyme replacement therapy (ERT) and allogeneic stem cell transplantation are causative and potentially curative attempts of treatment. ERT is still in development. First results using a knockout mouse model were promising and supported the initiation of a phase I clinical trial in the United States and Canada [46]. There is only one casuistic report of haplo-identical bone marrow transplantation in a patient with very severe hypophosphatasia. Initial response was reported favorable, however, the long-term outcome has not been reported.

\section{CONCLUSION}

Hypophosphatasia is a genetically inborn error of bone metabolism and its diagnosis often causes considerable problems. The exact metabolic mechanisms of primary and secondary sequels of TNSAP deficiency are not known in detail. Calcium pyrophosphate crystals seem to be a key player in inducing immunological cell activation resulting in acute and chronic inflammation.

Because there is a considerable variability of clinical symptoms, which may lead to a significant reduction in the quality of life, patients should be followed by a HPexperienced multidisciplinary team (paediatrician, radiologist, orthopedic surgeon, neurosurgeon, dentist, physiotherapist, nutritional therapist).

\section{ABBREVIATIONS}

$\begin{array}{ll}\mathrm{AP} & =\text { Alkaline phosphatase } \\ \mathrm{HP} & =\text { Hypophosphatasia } \\ \mathrm{IL}-1 \mathrm{R} & =\text { Interleukin-1 receptor } \\ \mathrm{IL}-1 \beta & =\text { Interleukin-1ß } \\ \mathrm{iPP} & =\text { Anorganic pyrophosphate } \\ \text { NALP3 } 3 \text { domain-containing protein 3 } & \text { Non-steroidal anti-inflammatory drug } \\ \text { NSAID } & =\text { Phosphoethanolamin } \\ \text { PEA } & =\text { Pyridoxal 5-phosphat } \\ \text { PLP } & =\text { Peripheral quantitative computed } \\ \text { pQCT } & \text { tomography } \\ \text { TLR } & \text { Toll-like receptor } \\ \text { TNSAP } & \text { Tissue non-specific alkaline phosphatase } \\ \text { TREM-1 } & \text { Triggering receptor expressed on myeloid }\end{array}$

\section{CONFLICT OF INTEREST}

None.

\section{REFERENCES}

[1] Whyte MP. Hypophosphatasia. In: Scriver CR, Beaudet AL, Sly S, Eds. The Metabolic and Molecular Basis of Inherited Disease. New York: McGraw-Hill 1995; pp. 4095-111.
[2] Whyte MP, Landt M, Ryan LM, et al. Alkaline phosphatase: placental and tissue-nonspecific isoenzymes hydrolyze phosphoethanolamine, inorganic pyrophosphate, and pyridoxal 5'phosphate. Substrate accumulation in carriers of hypophosphatasia corrects during pregnancy. J Clin Invest 1995; 95: 1440-5.

[3] Mornet E. Hypophosphatasia. Orphanet J Rare Dis 2007; 2: 40.

[4] Fedde KN, Whyte MP. Alkaline phosphatase (tissue-nonspecific isoenzyme) is a phosphoethanolamine and pyridoxal-5'-phosphate ectophosphatase: normal and hypophosphatasia fibroblast study. Am J Hum Genet 1990; 47: 767-75.

[5] Girschick HJ, Schneider P, Kruse K, Huppertz HI. Bone metabolism and bone mineral density in childhood hypophosphatasia. Bone 1999; 25: 361-7.

[6] Hessle L, Johnson KA, Anderson HC, et al. Tissue-nonspecific alkaline phosphatase and plasma cell membrane glycoprotein-1 are central antagonistic regulators of bone mineralization. Proc Natl Acad Sci USA 2002; 99: 9445-9.

[7] Shohat M, Rimoin DL, Gruber HE, Lachman RS. Perinatal lethal hypophosphatasia; clinical, radiologic and morphologic findings. Pediatr Radiol 1991; 21: 421-7.

[8] Baumgartner-Sigl S, Haberlandt E, Mumm S, et al. Pyridoxineresponsive seizures as the first symptom of infantile hypophosphatasia caused by two novel missense mutations (c.677T $>$ C, p.M226T; c.1112C $>$ T, p.T371I) of the tissuenonspecific alkaline phosphatase gene. Bone 2007; 40: 1655-61

[9] Girschick HJ, Seyberth HW, Huppertz HI. Treatment of childhood hypophosphatasia with nonsteroidal antiinflammatory drugs. Bone 1999; 25: 603-7.

[10] van den Bos T, Handoko G, Niehof A, et al. Cementum and dentin in hypophosphatasia. J Dent Res 2005; 84: 1021-5.

[11] Girschick HJ, Zimmer C, Klaus G, Darge K, Dick A, Morbach H Chronic recurrent multifocal osteomyelitis: what is it and how should it be treated? Nat Clin Pract Rheumatol 2007; 3: 733-8.

[12] Girschick HJ, Schneider P, Haubitz I, et al. Effective NSAID treatment indicates that hyperprostaglandinism is affecting the clinical severity of childhood hypophosphatasia. Orphanet J Rare Dis 2006; 1: 24.

[13] Brun-Heath I, Lia-Baldini AS, Maillard S, et al. Delayed transport of tissue-nonspecific alkaline phosphatase with missense mutations causing hypophosphatasia. Eur J Med Genet 2007; 50: 367-78.

[14] Akahoshi T, Murakami Y, Kitasato H. Recent advances in crystalinduced acute inflammation. Curr Opin Rheumatol 2007; 19: 14650 .

[15] Girschick HJ, Mornet E, Beer M, Warmuth-Metz M, Schneider P. Chronic multifocal non-bacterial osteomyelitis in hypophosphatasia mimicking malignancy. BMC Pediatr 2007; 7: 3.

[16] Martinon F, Petrilli V, Mayor A, Tardivel A, Tschopp J. Goutassociated uric acid crystals activate the NALP3 inflammasome. Nature 2006; 440: 237-41.

[17] Shi Y, Evans JE, Rock KL. Molecular identification of a danger signal that alerts the immune system to dying cells. Nature 2003; 425: 516-21.

[18] Bouchard L, de Medicis R, Lussier A, Naccache PH, Poubelle PE. Inflammatory microcrystals alter the functional phenotype of human osteoblast-like cells in vitro: synergism with IL-1 to overexpress cyclooxygenase-2. J Immunol 2002; 168: 5310-7.

[19] Chen CJ, Shi Y, Hearn A, et al. MyD88-dependent IL-1 receptor signaling is essential for gouty inflammation stimulated by monosodium urate crystals. J Clin Invest 2006; 116: 2262-71.

[20] Chuck AJ, Pattrick MG, Hamilton E, Wilson R, Doherty M. Crystal deposition in hypophosphatasia: a reappraisal. Ann Rheum Dis 1989; 48: 571-6.

[21] Dayer JM, Evequoz V, Zavadil-Grob C, et al. Effect of synthetic calcium pyrophosphate and hydroxyapatite crystals on the interaction of human blood mononuclear cells with chondrocytes, synovial cells, and fibroblasts. Arthritis Rheum 1987; 30: 1372-81.

[22] Drenth JP, van der Meer JW. The inflammasome--a linebacker of innate defense. N Engl J Med 2006; 355: 730-2.

[23] Hallegua DS, Weisman MH. Potential therapeutic uses of interleukin 1 receptor antagonists in human diseases. Ann Rheum Dis 2002; 61: 960-7.

[24] Jones AC, Chuck AJ, Arie EA, Green DJ, Doherty M. Diseases associated with calcium pyrophosphate deposition disease. Semin Arthritis Rheum 1992; 22: 188-202. 
[25] Lanzavecchia A, Sallusto F. Toll-like receptors and innate immunity in B-cell activation and antibody responses. Curr Opin Immunol 2007; 19: 268-74.

[26] Liu-Bryan R, Liote F. Monosodium urate and calcium pyrophosphate dihydrate (CPPD) crystals, inflammation, and cellular signaling. Joint Bone Spine 2005; 72: 295-302.

[27] Liu-Bryan R, Pritzker K, Firestein GS, Terkeltaub R. TLR2 signaling in chondrocytes drives calcium pyrophosphate dihydrate and monosodium urate crystal-induced nitric oxide generation. J Immunol 2005; 174: 5016-23.

[28] Mariathasan S, Weiss DS, Newton K, et al. Cryopyrin activates the inflammasome in response to toxins and ATP. Nature 2006; 440: 228-32.

[29] Mariathasan S, Monack DM. Inflammasome adaptors and sensors: intracellular regulators of infection and inflammation. Nat Rev Immunol 2007; 7: 31-40.

[30] Murakami Y, Akahoshi T, Hayashi I, et al. Induction of triggering receptor expressed on myeloid cells 1 in murine resident peritoneal macrophages by monosodium urate monohydrate crystals. Arthritis Rheum 2006; 54: 455-62.

[31] Ogura Y, Sutterwala FS, Flavell RA. The inflammasome: First line of the immune response to cell stress. Cell 2006; 126: 659-62.

[32] Reginato AM, Olsen BR. Genetics and experimental models of crystal-induced arthritis. Lessons learned from mice and men: is it crystal clear? Curr Opin Rheumatol 2007; 19: 134-45.

[33] Schiff MH. Role of interleukin 1 and interleukin 1 receptor antagonist in the mediation of rheumatoid arthritis. Ann Rheum Dis 2000; 59 (Suppl 1): i103-8.

[34] Sutterwala FS, Ogura Y, Flavell RA. The inflammasome in pathogen recognition and inflammation. J Leukoc Biol 2007; 82: 259-64.
[35] Takeda K, Akira S. Toll-like receptors in innate immunity. Int Immunol 2005; 17: 1-14.

[36] Ting JP, Kastner DL, Hoffman HM. CATERPILLERs, pyrin and hereditary immunological disorders. Nat Rev Immunol 2006; 6: 183-95.

[37] Uematsu S, Akira S. Toll-like receptors and innate immunity. J Mol Med 2006; 84: 712-25.

[38] Dinarello CA. Biologic basis for interleukin-1 in disease. Blood 1996; 87: 2095-147.

[39] Ferrari D, Pizzirani C, Adinolfi E, et al. The P2X7 receptor: a key player in IL-1 processing and release. J Immunol 2006; 176: 3877 83.

[40] Stylianou E, Saklatvala J. Interleukin-1. Int J Biochem Cell Biol 1998; 30: 1075-9.

[41] Collmann H, Mornet E, Gattenlohner S, Beck C, Girschick H. Neurosurgical aspects of childhood hypophosphatasia. Childs Nerv Syst 2009; 25: 217-23.

[42] Beck C, Morbach H, Richl P, Stenzel M, Girschick HJ. How can calcium pyrophosphate crystals induce inflammation in hypophosphatasia or chronic inflammatory joint diseases? Rheumatol Int 2009; 29: 229-38.

[43] Girschick HJ, Raab P, Surbaum S, et al. Chronic non-bacterial osteomyelitis in children. Ann Rheum Dis 2005; 64: 279-85.

[44] Camacho PM, Painter S, Kadanoff R. Treatment of adult hypophosphatasia with teriparatide. Endocr Pract 2008; 14: 204-8.

[45] Whyte MP, Mumm S, Deal C. Adult hypophosphatasia treated with teriparatide. J Clin Endocrinol Metab 2007; 92: 1203-8.

[46] Millan JL, Narisawa S, Lemire I, et al. Enzyme replacement therapy for murine hypophosphatasia. J Bone Miner Res 2008; 23: 777-87.

(C) Beck et al.; Licensee Bentham Open.

This is an open access article licensed under the terms of the Creative Commons Attribution Non-Commercial License (http://creativecommons.org/licenses/by$\mathrm{nc} / 3.0 /)$, which permits unrestricted, non-commercial use, distribution and reproduction in any medium, provided the work is properly cited. 